\title{
Viewpoint
}

\section{Management of NSAID induced gastrointestinal disturbance}

\author{
M DOHERTY. ${ }^{1}$ R H HUNT. ${ }^{2}$ M J S LANGMAN. ${ }^{3}$ R E POUNDER. ${ }^{4}$ \\ R I RUSSELL, ${ }^{5}$ D STURROCK, ${ }^{6}$ AND A K THOULD
}

From the I'Department of Rheumatology, Nottingham City Hospital; the 'Division of Gastroenterology, McMaster University Medical Centre, Hamilton, Ontario, Canada; the ${ }^{3}$ Queens Medical Centre, Nottingham; the ${ }^{4}$ Academic Department of Medicine, Royal Free Hospital, London; the ${ }^{5}$ Department of Gastroenterology, Glasgow Royal Infirmary; the ${ }^{6}$ Centre for Rheumatic Diseases, Glasgow Royal Infirmary; and the ${ }^{7}$ Department of Rheumatology, Royal Cornwall Hospital, Truro

Key words: peptic ulceration, dyspepsia, gastric erosion, rheumatoid arthritis, osteoarthritis. $\mathrm{H}_{2}$ antagonists.

The value of treatment with non-steroidal antiinflammatory drugs (NSAIDs) is suggested by their widespread use, over 22 million prescriptions being issued each year. ${ }^{1}$ Patients commonly suffer from adverse gastrointestinal effects, however. Avoidance of these would be eased if we had a fuller understanding of basic mechanisms and predisposing factors. Assessment is further hindered because peptic ulcer is common in the elderly even without NSAID treatment, there are no characteristic symptom patterns, patients with connective tissue diseases may be inherently more prone to gastrointestinal damage ${ }^{2-4}$ there is a wide range of disorders for which NSAIDs are indicated, be it long term (rheumatoid arthritis, osteoarthritis) or acutely (soft tissue injuries), and there are at least 18 available generic NSAIDs.

\section{Ulcer frequency}

Duodenal ulcer has been accepted as a disease of the young or middle aged, but recent data suggest that the incidence of both gastric and duodenal ulcer, at least as judged by perforation rates, has increased markedly in the United Kingdom in the elderly over the past 25 years, whereas it has fallen substantially in younger people. ${ }^{5}$ The reasons for this change are not clear, and we are left with the impression that there are specific factors which have made elderly people more prone to peptic ulceration and its

Accepted for publication 17 March 1987

Correspondence to $\mathrm{Dr} M$ Doherty. Dept of Rheumatology.

Nottingham City Hospital. Nottingham NG5 IPB. complications. Altered smoking habits in the elderly $\vec{\oplus}$ seem unlikely to account for the change, buto increased use of NSAIDs may be partially responsible.

The prevalence of peptic ulcer has been reported to be $29 \%$ and $32 \%$ in osteoarthritis and rheumatoid arthritis respectively. ${ }^{\circ}$ In a random sample ofö patients with rheumatoid arthritis who were receiv- $\cong$ ing NSAIDs, $36 \%$ were found to have peptic ulcer. $\overrightarrow{\vec{O}}$ with gastric ulcer and duodenal ulcer of equal $\$$ prevalence (Sturrock and Russell, in preparation). The prevalence of gastrointestinal lesions is higher in patients receiving more than one NSAID. suggesting a cumulative risk. ${ }^{6} 7$

\section{Symptom patterns}

Patients taking NSAIDs may suffer from dyspeptic symptoms without having ulcers, or have an ulcer 5 with or without dyspeptic symptoms, and they may suffer the ulcer complications of bleeding or perforation, often without any premonitory symptoms. $\widetilde{\sigma}$ All these patterns of disease, however, can be foundn in otherwise healthy people. A high prevalence of asymptomatic gastric ulcer $(43 \%$, women: $18 \% \omega$ men) and duodenal ulcer ( $41 \%$, women: $29 \%$, men has been reported." Asymptomatic recurrence of duodenal ulcer was reported to be almost aso frequent as symptomatic recurrence, "and two thirds of patients with a recurrence of gastric ulcer had at complete lack of symptoms. ${ }^{10}$ There is evidence thatत् the incidence of asymptomatic ulceration may be higher in patients with arthritis or those receiving NSAIDs, or both. In a series of rheumatoid patients 
with gastric ulcer, $56 \%$ were asymptomatic (Sturrock and Russell, in preparation).

If ulcer complications were to be observed to occur frequently in NSAID takers in the absence of premonitory dyspeptic symptoms it would be difficult to determine whether NSAID users were indeed prone to painless ulceration, or whether the proportion of patients with dyspepsia was reduced because those who complained of gastrointestinal symptoms would have had NSAID treatment withdrawn, thus averting ulcer complications. It is also possible that the analgesic properties of NSAIDs mask the symptoms of dyspepsia, ${ }^{11}$ or that patients with arthritis are used to pain and their disease expectation includes gastrointestinal upset. In these circumstances it is difficult to interpret data suggesting that a high proportion of patients taking NSAIDs have ulcers without dyspeptic symptoms unless the sample of NSAID takers is a random cross section of all those given treatment.

\section{Coincident disease in arthritis}

It is difficult to determine whether patients suffering from one disease are at risk of another. Postmarketing surveillance has shown that the greater intensity of clinical surveillance, which is an inevitable consequence of disease, will increase the chances of a second disease being recognised. ${ }^{12}$ Secondly, if an association between arthritis and ulcer is sought by examining the prevalence of ulcer in arthritis, and of arthritis in ulcer patients, the chances of detecting associations will be increased, but a spuriously high level of association by comparison with a reference value will also be noted. ${ }^{13}$

There have nevertheless been repeated suggestions that the patient with arthritis, particularly rheumatoid disease, is inherently susceptible to peptic ulceration, ${ }^{2-4}$ though whether any increase represents a special property of the rheumatoid process, or is a general feature to be expected in those who are, say, marginally malnourished, is not clear. Platelet activating factor has been proposed as a mediator in the production of stress ulceration of the gastrointestinal tract and may explain the prevalence of gastrointestinal disturbance in chronic painful diseases such as rheumatoid arthritis. ${ }^{14}$

\section{Ulcer and dyspepsia in NSAID takers}

Dyspeptic symptoms commonly complicate NSAID treatment, the prevalence varying with the intensity of treatment and probably with NSAID potency. NSAIDs have been referred to as blocking the prostaglandin-buttressed defences of the gastric mucosa. ${ }^{15}$ Prostaglandins are known to increase gastric mucosal blood flow, ${ }^{16}$ bicarbonate secretion, ${ }^{17}$ mucus thickness, ${ }^{18}$ and to enhance restitution of mucosal damage. ${ }^{19}$ Experimentally NSAIDs have been shown to increase acid output, ${ }^{20}$ decrease mucus biosynthesis, ${ }^{21}$ and diminish bicarbonate production. ${ }^{22}$ In addition, NSAID treatment in animals predisposes to experimental ulceration. ${ }^{182123}$ Persuasive as these data may be they do not necessarily imply that treatment with NSAIDs causes ulcer or ulcer complications in man.

A significant proportion of patients with ulcer bleeding or perforation has nevertheless been found to have taken NSAIDs. ${ }^{24} 25$ This proportion was found to be larger than in inpatient or community controls matched by age and sex, with an approximately threefold increase in risk for both gastric and duodenal ulcer in individuals aged 60 and over. ${ }^{26}$ Confounding seems unlikely to explain the differences, but the studies do not allow us to conclude whether NSAID ingestion predisposes to ulceration per se, or to complications in those with established ulcer. Caruso and Bianchi Porro, however, in a prospective endoscopic study noted that gastric erosions increased markedly in NSAID takers when endoscopic findings before and after treatment were compared. ${ }^{6}$ There was an increased proportion of NSAID takers in patients with bleeding ulcer compared with controls, in contrast with the relative lack of ulcer complications in short term controlled trials of NSAID treatment. Furthermore, when groups of 6000 to 12000 patients taking particular NSAIDs were followed up in post-marketing surveillance studies no differences in ulcer complication rates were noted in those given any of five different NSAIDs nor between rates in the absence or presence of treatment with these individual agents. ${ }^{27}$

The apparently incompatible results of case control studies suggesting that NSAIDs may cause ulcer complications, and surveillance studies suggesting that they do not, can be reconciled if the likely incidence of ulcer complications is taken into account. Some 30000 episodes of haematemesis or melaena, or both, occurring each year in the United Kingdom lead to hospital admission, or about 1 in 2000 of the population. About half of these are due to gastric or duodenal ulcer, or about 1 episode of ulcer bleeding for every 4000 population of all ages each year. If we suppose that the average NSAID prescription has a duration of one month then the ordinary expectation of an episode of ulcer bleeding might be about 1 in every 48000 monthly prescription periods. Thus in a population of all ages a threefold multiplication of risk would not be discernible during surveillance studies. General figures suggest that a tripling of the risk in individuals over 60 years of age would in effect mean that one 
episode of ulcer bleeding or perforation might occur in association with every 3000 NSAID prescriptions in that age group (the chances of ulcer complications being greater in the elderly than in the young). If such calculations are correct it suggests we need to scrutinise more closely the need for NSAID treatment in elderly patients who do not have a severe arthropathy. Treatment should not be withheld from those with active rheumatoid disease; and available evidence suggests not that these patients are particularly at risk, but that the elderly with nondescript complaints or with osteoarthritis may be prone, at least, to ulcer complications. ${ }^{26}$

The total number of NSAID prescriptions issued has increased by over 10 million in the UK in recent years, with the elderly being most likely to receive treatment, but this rise probably accounts for a fifth to a quarter of the increase in total perforations noted. ${ }^{5}$ Nevertheless the coincidence between an increasing incidence of ulcer perforation in the elderly, and a rising rate of NSAID consumption in the same age group, suggests that it might be wise to keep the NSAID dosage as low as possible.

\section{Investigation}

There are no simple guidelines to separate those needing investigation of gastrointestinal symptoms from those who do not. The choice is usually made on symptomatic grounds even though there seems to be a high incidence of asymptomatic ulcer in patients with arthritis. Likewise there are no clear grounds for choosing between endoscopy and double contrast radiology examination, though experience in this age group favours endoscopy, particularly as a means of detecting small mucosal lesions and erosions and in examining the duodenal cap efficiently. Elderly and arthritic patients find endoscopy easier and generally prefer it to a barium meal, which requires considerable mobility on a hard $x$ ray table to obtain optimal films. Modern fibre optic endoscopes are safe even in patients with advanced rheumatoid disease.

\section{Management}

When a patient taking a NSAID develops dyspepsia most clinicians will withdraw treatment altogether, or alternatively substitute another NSAID, or prescribe peptic ulcer therapy. The decision between these strategies has no rational basis. If the adverse gastrointestinal effects of NSAIDs, which have been reviewed by Rainsford, ${ }^{28}$ are associated with their anti-inflammatory properties (whether or not this is due to cyclo-oxygenase inhibition) then substitution of a similar drug should make little difference to symptoms except through changes in placebo effect although tolerance may develop.

Another strategy is to substitute a pro-drug needing hepatic activation or to use suppositorye treatment; both manoeuvres would be soundly based if NSAID side effects were local rather than systemic, but we do not know if this is true aso indomethacin suppositories are associated withes gastric mucosal damage.

For the arthritic patient with an ulcer who needsto continue NSAID treatment, most clinicians arec likely to choose an $\mathrm{H}_{2}$ receptor antagonist such as cimetidine or ranitidine. Ulcer healing has been⿳亠口冋 shown to occur despite continued NSAID treatment, ${ }^{29}$ and in one study the average healingo time is similar whether an $\mathrm{H}_{2}$ receptor antagonist oro sucralfate is used. ${ }^{30}$

The dilemma remains, however, as to whether prophylactic therapy should be undertaken forpatients who require to take NSAIDs long term The $\mathrm{H}_{2}$ receptor antagonists have been shown tô prevent experimentally induced NSAID ulceration? in animals ${ }^{31}$ and salicylate induced erosions ${ }^{32}$ and NSAID induced blood loss in human volunteers. ${ }^{3300}$ Sucralfate has been claimed to have a protective effect against NSAID induced injury in man, ${ }^{34}$ and theoretically the new synthetic prostaglandin ana-s logues misoprostol and enprostil would be logica agents to use because of their ability both to inhibit gastric acid secretion and to increase a number of factors shown to be important in the maintenance of gastric mucosal integrity. Limited experimenta $\vec{P}$ evidence in human volunteers shows that these prostaglandins can also protect the gastric mucosa. from experimental damage, ${ }^{23}$ but there is as yet now evidence to confirm their role or superiority overo established treatments in patients.

Perhaps of more concern is the objective of prophylactic therapy. Is it to prevent the gastrointes tinal symptoms associated with NSAID treatment? If so, study design to allow for the tolerance which? develops is essential before conclusions are drawno Is it to prevent gastric erosions observed with treatment? If so, we need to know much more of their natural history, as those seen with salicylater treatment, like symptoms, reduce with time; and whether those that persist will develop into ulcers ${ }_{\sigma}^{\omega}$ Lastly, will prophylactic treatment prevent the development of peptic ulcer in arthritic patients an\& especially its complications? Very large clinical trial\$ involving many thousands of patients over severa [ years will be necessary to answer this question. $\overrightarrow{0}$

In the meantime those patients receiving longD term NSAID therapy who have an ulcer should be treated and NSAIDs may be continued. It would be wise to ascertain ulcer healing by endoscopy and io 
this small group prophylactic therapy is justifiable. For the remainder, long term prophylaxis is best reserved for those with troublesome symptoms until the results of further studies are available.

This viewpoint was developed from a roundtable meeting supported by SK \& F.

\section{References}

1 CSM Update. Non-steroidal anti-inflammatory drugs and serious gastrointestinal adverse reactions-1. Br Med J 1986; 292: 614.

2 Atwater E C, Mongan E S, Wieche D R, Jacox R F. Peptic ulcer and rheumatoid arthritis: a prospective study. Arch Intern Med 1965; 115: 184-9.

3 Cobb S, Hall W. Newly identified cluster of diseasesrheumatoid arthritis, peptic ulcer and tuberculosis. JAMA 1965; 193: 1077-9.

4 Marcolongo R, Bayeli P F, Montagnani M. Gastrointestinal involvement in rheumatoid arthritis: biopsy study. $J$ Rheumatol 1979; 6: 163-73

5 Walt R, Katschinski B, Logan R, Ashley J, Langman M. Rising frequency of ulcer perforation in elderly people in the United Kingdom. Lancet 1986; i: 489-92.

6 Caruso I, Bianchi Porro G. Gastroscopic evaluation of antiinflammatory agents. $\mathrm{Br}$ Med $J$ 1980; 280: 75-8.

7 Rainsford K D. Side-effects of anti-inflammatory analgesic drugs: epidemiology and gastrointestinal tract. Trends in Pharmacological Sciences 1984; 5: 156-9.

8 Allan R, Dykes P. A study of the factors influencing mortality rates from gastrointestinal haemorrhage. $Q J$ Med 1976; 15: 533-50.

9 Boyd E J S, Wilson J A. Wormsley K G. Effects of treatment compliance and overnight gastric secretion on outcome of maintenance therapy of duodenal ulcer with ranitidine. Scand $J$ Gastroenterol 1983; 18: 193-200.

10 Jorde R. Bostad L. Burhol P G. Asymptomatic gastric ulcer: a follow-up study in patients with previous gastric ulcer disease. Lancet 1986; i: 119-21.

11 Mellem H, Stave R. Myren J, et al. A masking effect by nonsteroid anti-inflammatory drugs (NSAID) on symptoms in patients with ulcer and hematemesis and or melaena? Scand $J$ Gastroenterol [Suppl] 1985; 20: 15.

12 Colin-Jones D G, Langman M J S, Lawson D H, Vessey M P. Post-marketing surveillance of the safety of cimetidine: twelvemonth morbidity report. $Q J$ Med 1985; 54: 253-68.

13 Donaldson R M. Factors complicating observed associations between peptic ulcer and other diseases. Gastroenterology 1975: 68: $1608-16$.

14 Rosan A C. Whittle B J R. Wallace J L. Potency of platelet activation factor on the stomach. Nature 1986; 319: 54.

15 Spiro H M. Is the steroid ulcer a myth? N Engl J Med 1983; 309: 45-7.

16 Whittle B J R. Actions of prostaglandins on gastric mucosal blood flow. In: Fielding L P, ed. Gastrointestinal mucosal blood flow. London: Churchill Livingstone, 1980: 180-91.
17 Smeaton L A, Hirst B H. Allen A, Garner A. Gastric and duodenal $\mathrm{HCO}_{3}^{-}$transport in vivo: influence of prostaglandins. Am J Physiol 1983; 245: G751-9.

18 McQueen S, Hutton D, Allen A, Garner A. Gastric and duodenal surface mucus gel thickness in rat: effects of prostaglandins and damaging agents. Am J Physiol 1983; 245: G388-93.

19 Lacy E R, Ito S. Ethanol-induced insult to the superficial rat gastric epithelium: a study of damage and rapid repair. In: Allen A, Flemström G, Garner A, Silen W, Turnberg L A, eds. Mechanisms of mucosal protection in the upper gastrointestinal tract. New York: Raven Press, 1984: 49-56.

20 Feldman M. Colturi T J. Effect of indomethacin on gastric acid and bicarbonate secretion in humans. Gastroenterology 1984; 87: $1339-43$.

21 Rainsford K D. Effects of anti-inflammatory drugs on mucus production: relationship to ulcerogenesis. In: Pfeiffer $\mathrm{C} \mathrm{J}$, ed. Drugs and the peptic ulcer. Vol 2. Florida: CRC Press, 1982: 43-54.

22 Selling J A, Hogan D L, Koss M A, Isenberg J I. Human proximal versus distal duodenal bicarbonate secretion: effect of endogenous prostaglandin synthesis. Gastroenterology 1985; 88: $1580 \mathrm{~A}$

23 Hawkey C J, Rampton D C. Prostaglandins and the gastrointestinal mucosa; are they important in its function, disease or treatment? Gastroenterology 1985; 89: 1162-88.

24 Collier D St J, Pain A. Non-steroidal anti-inflammatory drugs and peptic ulcer perforation. Gut 1985; 26: 359-63.

25 O'Brien J D, Burnham W R. Bleeding from peptic ulcers and use of non-steroidal anti-inflammatory drugs in the Romford area. $\mathrm{Br}$ Med J 1985; 291: 1609-10.

26 Somerville K, Faulkner G, Langman M. Non-steroidal antiinflammatory drugs and bleeding peptic ulcer. Lancet 1986; i: 462-4.

27 Inman W H W. Comparative study of five NSAIDs. Postmarketing Surveillance News 1985; 3: 3-12. (Drug surveillance research unit. University of Southampton.)

28 Rainsford K D. Comparison of the gastric ulcerogenic activity of new non-steroid anti-inflammatory drugs in stressed rats. $\mathrm{Br}$ J Pharmacol 1981; 73: 226-7P.

29 Croker J R, Cotton P B, Boyle A C. Kinsella P. Cimetidine for peptic ulcer in patients with arthritis. Ann Rheum Dis 1980; 39: 275-8.

30 Molchow-Møller A, Manniche C, Andersen J R, et al. Does cessation of NSAID-therapy influence the healing of peptic ulcer in rheumatic patients? Scand J Gastroenterol [Suppl] 1985; 20: 53.

31 Mann N S. Drug induced acute erosive gastritıs: its preventıon by antacid, metiamide and cimetidine. Am J Proctol 1977; 28: 23-8.

32 Kimmey M B. Silverstein F E. Mucosal protective effects of cimetidine. Postgrad Med 1985; (Nov suppl): 85.

33 Silverstein F E, Saunders D R, Chapman R W, Levine D S. Cimetidine mucosal protection: a dose response study. Gastrointest Endosc 1985; 31: 136.

34 Tesler M A, Lim E S. Protection of gastric mucosa by sucralfate from aspirin-induced erosions. J Clin Gastroenterol 1981; 3 (suppl 2): 175-9. 